\title{
101 lakes - lentic fish community monitoring using eDNA metabarcoding
}

\author{
Bernd Hänfling $\ddagger$, Nigel Willby§, Lori Lawson-Handleyl, Graham Sellers \\ $\ddagger$ The University of Hull, Hull, United Kingdom \\ $\S$ University of Stirling, Stirling, United Kingdom \\ | University of Hull, Hull, United Kingdom
}

Corresponding author: Bernd Hänfling (b.haenfling@hull.ac.uk)

Received: 03 Mar 2021 | Published: 04 Mar 2021

Citation: Hänfling B, Willby N, Lawson-Handley L, Sellers G (2021) 101 lakes - lentic fish community monitoring using eDNA metabarcoding. ARPHA Conference Abstracts 4: e65438. https://doi.org/10.3897/aca.4.e65438

\begin{abstract}
We have recently developed and deployed methods for environmental DNA (eDNA) based monitoring of lake fish communities in the UK. This approach combines eDNA with modern High-Throughput-Sequencing technology, so-called eDNA metabarcoding. This noninvasive method has proven to be more effective at detecting elusive species than established invasive surveying techniques such as electro fishing or fyke netting and can provide meaningful semi-quantitative abundance estimates. The UK Environment Agencies have funded the collection of an eDNA meta-barcoding data set of vertebrates from 101 UK lakes covering a broad spectrum of environmental conditions Fig. 1. This dataset is based on analysing 20 water samples per lake and has successfully been used to develop a WFD compatible water quality assessment tool. In its current form this tool is suitable for reporting the status of fish in water bodies where eutrophication is the dominant pressure.
\end{abstract}



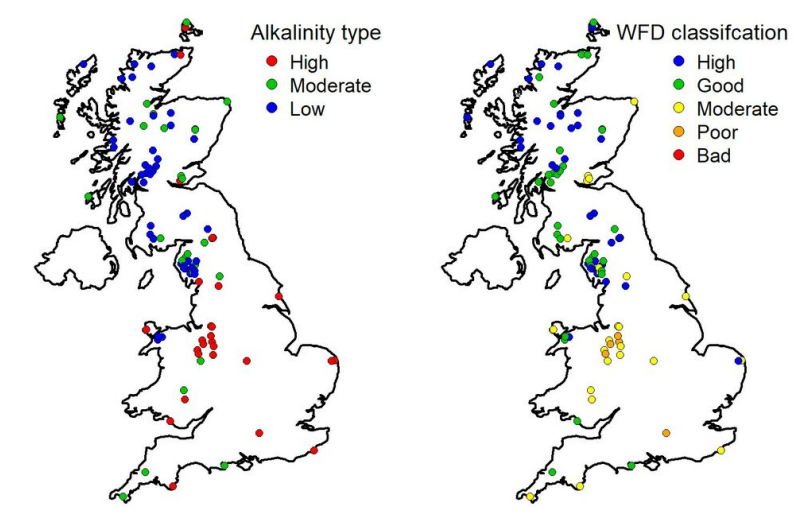

Figure 1. doi

Distribution and characteristics of 101 UK lakes with associated eDNA data. Shown are alkalinity type (left) and existing WFD classification (right) for each lake. Redrawn based on data from Willby et al. (2019)

DNA is not homogeneously distributed in lentic environments and hence the detection of species relies on the collection of an adequate number of samples from a water body to capture the eDNA signal. Previous analyses on a subset of lakes have indicated that the number of samples used for the 101 lake fish data set is more than sufficient to reliably estimate species richness of lakes, but it is unclear how exactly reduced sampling effort affects other biodiversity estimates and inferences made about water quality. As the number of samples determines the cost of monitoring programmes it is essential that the sampling effort is optimised for a specific monitoring objective. The objective of this study was to explore the effect a reduced sampling effort would have on various biological inferences using algorithmic and statistical resampling techniques. with a much lower number of samples. For example, almost $90 \%$ of lakes achieved a sample coverage of $95 \%$ with only 10 samples. However, rare species are more often missed with fewer samples, with implications for monitoring programs of invasive or endangered species. Estimates of community composition and the ecological quality ratio (EQR) responded slowly to decreasing sampling effort. For example, subsets of 10 samples were in most cases much more closely related to each other than to sample sets from other lakes and showed very similar Ecological Quality Ratios. These results are able to inform the design of eDNA sampling strategies, so that these can be optimised to achieve specific monitoring goals.

\section{Presenting author}

Bernd Hänfling 


\section{Presented at}

1st DNAQUA International Conference (March 9-11, 2021)

\section{Acknowledgements}

The Agencies that own the data are Environment Agency, Natural Resources Wales and Scottish Environment Protection Agency. In addition Scottish Natural Heritage have provided advice and Natural England have funded the project. A number of scientists from the University of Hull, the University of Stirling and the Centre for Ecology \& Hydrology have contributed to the collection of the data. The individuals to be acknowledged are:

Environment Agency:

Dr. Graeme Peirson, Dr. Kerry Walsh, Keith Bell

Natural Resources Wales:

Dr. Tristan Hatton-Ellis

Scottish Environment Protection Agency:

Dr. Alistair Duguid, Dr. Willie Duncan, Sean Morrison

Scottish Natural Heritage:

Prof. Colin Bean

Natural England:

Dr. Ruth Hall, Chris Mainstone, Dr. Katie Clark, Debbie Leatherland, Dave Ottewell

University of Hull:

Dr Lori Lawson-Handley, Dr Jianlong Li, Dr Rosetta Blackman, Dr Harriet Johnson, Dr Rob Donnelly, Dr Lynsey Harper, Dr Marco Benucci, Dr Helen Kimbell, Cristina Di Muri, Nathan Griffith, Dr Christoph Hahn, Dr David Lunt, Dr Graham Sellers, Dr Bernd Hänfling

University of Stirling:

Prof Nigel Willby, Dr Alan Law, Dr Colin Bull

Centre for Ecology \& Hydrology

Dr lan Winfield, Dr Daniel Read, Dr Anna Oliver, Ben James, Janice Fletcher

Without exceptions land owners and fishery owners have supported the data collection through allowing access to the water bodies. A number of EA and SEPA officers helped 
during planning and evaluated the eDNA data against previous knowledge of fish distribution.

Prof Chris Jerde (University of California, Sant Barbara) has provided advice on the data analysis. 